\title{
Transmittance Spectrum of Unbranded Sunglasses Using Spectrophotometer
}

\author{
Huseyin Gursoy ${ }^{*}$, Hikmet Basmak ${ }^{1}$, Hamza Esen ${ }^{2}$, Ferhan Esen ${ }^{2}$ \\ ${ }^{1}$ Eskisehir Osmangazi University Medical Faculty, Department of Ophthalmology, Eskisehir, Turkey \\ ${ }^{2}$ Eskisehir Osmangazi University Medical Faculty, Department of Biophysics, Eskisehir, Turkey \\ Email: hhgursoy@hotmail.com
}

Received 2 January 2015; accepted 27 January 2015; published 29 January 2015

Copyright (C) 2015 by authors and Scientific Research Publishing Inc.

This work is licensed under the Creative Commons Attribution International License (CC BY).

http://creativecommons.org/licenses/by/4.0/

c) (i) Open Access

\begin{abstract}
Background: The sunglass standards are not strictly implemented in many countries except Australia. The purpose of the study was to evaluate the optical properties of unbranded sunglasses for light transmittance. Methods: Unbranded sunglasses with no information about their specifications were included. They were allocated to two groups based on their prices; the ones $>25$ US\$ (Group A) and the cheaper ones (Group B). Their transmittance spectrum was measured between $190 \mathrm{~nm}$ and $900 \mathrm{~nm}$ using a double beam scanning spectrophotometer. The European standard for sunglasses was used to evaluate their compliance regarding ultraviolet radiation (UVR) transmittance and minimum requirement for wearing when driving. Results: Thirty-eight sunglasses (Group $A=20$ and Group $B=18$ ) were evaluated. Four sunglasses in each group were non-compliant. Percentage transmittance of visible light was $<8 \%$ in five sunglasses of Group $A$ and in three of Group B, so these were not appropriate to wear when driving. Totally six sunglasses of Group A and five of Group B were non-compliant and/or inappropriate to wear when driving. Conclusions: Based on our findings about their UVR protection and visible light transmittance \%, eye care professionals must warn people against the use of unbranded sunglasses without any information about their specifications.
\end{abstract}

\section{Keywords}

Sunglass, Spectrophotometer, Transmittance Spectrum, Ultraviolet Radiation, Visible Light

\section{Introduction}

Ultraviolet (UV) radiation (UVR) is defined as invisible light rays with a wavelength of less than approximately $400 \mathrm{~nm}$. Three types of UVR based on their wavelengths: UV-A (315 to $400 \mathrm{~nm}$ ), UV-B (280 to $315 \mathrm{~nm}$ ), and

\footnotetext{
*Corresponding author.
} 
UV-C (<280 nm) exist [1]. UV-C radiation does not penetrate the atmosphere's ozone layer, while some UV-A and UV-B reach the earth [2]. Both UV-A and UV-B may cause many dermatologic and ocular disorders [1] [3]-[6].

Although many people consider sunglasses as a symbol of style and trend, they are mainly produced to protect our eyes and the skin around the eyes from the harmful effects of the UVR. In our opinion the majority of people, including many eye care professionals are not aware of these regulations and just prefer the cheaper and more fashionable sunglasses. Over the counter sunglasses without any information about their specifications are being sold all over the world. Our aim was to evaluate the optical properties of unbranded sunglasses for light transmittance.

\section{Material and Methods}

The study was conducted at our University Medical Faculty, Department of Biophysics. Unbranded brown sunglasses that were purchased in optical shops or supermarkets in the city centre were included. Only the sunglasses with no information about their specifications were studied. They were allocated into two groups based on their prices; the ones over 25 US\$ (Group A) and the cheaper ones less than 25 US\$ (Group B).

Absorbance is the measure of the quantity of light that a sample neither transmits nor reflects, whereas the transmittance is the ratio of the intensity of the light that has passed through the sample to the intensity of the light when it entered it. The transmittance of a sample is given as a percentage. In the current study, the transmittance spectrum of the sunglasses was measured between 190 and $900 \mathrm{~nm}$ using a double beam scanning spectrophotometer (ATI Unicam, Cambridge and model UV2-100) with a $1.5 \mathrm{~nm}$ spectral bandwidth. The instrument measured the absorbance spectrum through the sunglasses (test sample) relative to air (reference sample). The measurements are sent to a computer interface for graphical analysis. Percentage transmittance was plotted on the y axis against the wavelength in $\mathrm{nm}$ on the $\mathrm{x}$ axis. The \% of luminous transmittance (LT) at visible spectral range and the \% of UV-A and UV-B transmittance were recorded.

The sunglasses were categorized according to their range of LT at visible spectral range based on the European standard for sunglasses [7]. Category 4 includes the sunglasses with $<8 \%$ LT, Category 3 the ones with $8 \%$ - 18\%, Category 2 the ones with $18 \%$ - 43\%, Category 1 the ones with $43 \%$ - $80 \%$ and Category 0 with $80 \%$ $100 \%$. The European standard for sunglasses allows UV-B transmittance to reach $10 \%$ of all LT in all sunglasses categories [7]. UV-A transmittance has to be no more than the LT for the categories 0,1 and 2, while it should not exceed $50 \%$ of all the LT for the categories 3 and 4 [7]. The sunglasses that did not meet the criteria for compliance with these standards were recorded.

Statistical analysis was performed using SPSS 15.0 (SPSS Inc., Chicago, IL, USA). The results of two groups were compared by the independent samples t-test or chi-square test. Significance was attributed when $p<0.05$.

\section{Results}

Group A included twenty brown unbranded sun glasses with a price of $>25$ US\$ and Group B eighteen brown unbranded sun glasses with a price of $<25$ US\$.

The graph of the \% transmittances of Group B in the wavelength range of 250 - 600 nm was shown in Figure 1.

The mean \% of LT was $15.8 \pm 8.3$ and $16.6 \pm 6.9$ for Group A and B, respectively (range 3.1\% - 32\% in Group A vs. 4.5\% - 31.2\% in Group B) $(p=0.2)$. The categories of sunglasses based on their LT were shown in Table 1. Five sunglasses of Group A and three of Group B had LT of $<8 \%$, so fell in Category $4(p=0.4)$. These were not appropriate to wear when driving.

UV-B radiation was blocked appropriately according to the European standard in all sun glasses [7]. However, four sun glasses in each group was non-compliant with the European standard regarding the UV-A blockage ( $p=$ 0.6) [7]. The categories for each non-compliant sun glasses were shown in Table 2. Eleven out of thirty-eight sunglasses (29\%); six sunglasses in Group A and five sunglasses in Group B were non-compliant with the European standard and/or lacking the necessary warning against wearing when driving $(p=0.5)$.

\section{Discussion}

In the current study including unbranded sunglasses, we found that four out of twenty sunglasses in Group A and 


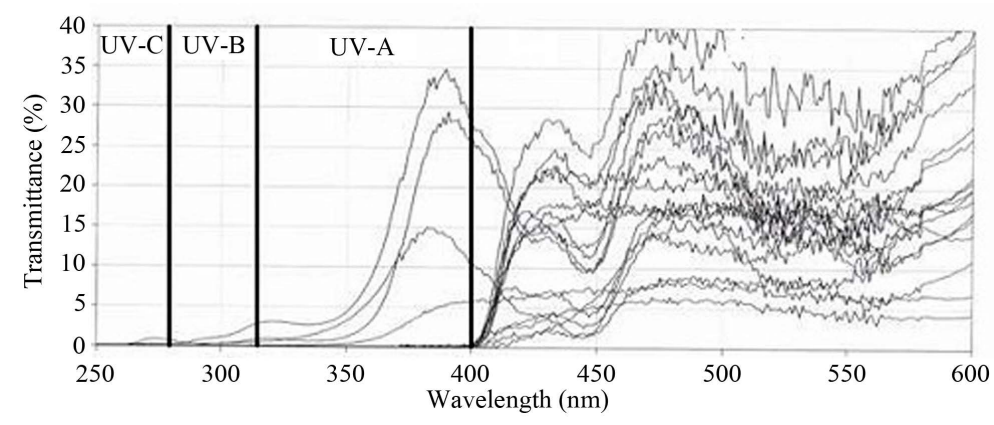

Figure 1. Transmittances of Group B in the wavelength range of $250-600 \mathrm{~nm}$.

Table 1. The categories of sunglasses based on their luminous transmittance.

\begin{tabular}{ccc}
\hline Category for the sun glasses & Group A $(\mathrm{n}=20)$ & Group B (18) \\
\hline 4 (Luminous transmittance $<8 \%$ ) & 5 & 3 \\
3 (Luminous transmittance $8 \%-18 \%)$ & 7 & 9 \\
2 (Luminous transmittance $18 \%-43 \%)$ & 8 & 6 \\
\hline
\end{tabular}

Table 2. The categories for each non-compliant sun glasses.

\begin{tabular}{ccc}
\hline Category of the sun glasses & Group A $(\mathrm{n}=20)$ & Group B (18) \\
\hline 4 & 0 & 1 \\
3 & 3 & 1 \\
2 & 1 & 2 \\
\hline
\end{tabular}

four out of eighteen in group B were non-compliant with the European standard for sunglasses. In addition to this finding, \% transmittance of visible light was less than 8\% in five sunglasses in Group A and three in Group B. Regardless of their prices, $29 \%$ (11/38) of the sunglasses were not appropriate to protect the eyes from UVR hazards and/or were not appropriate to use when driving.

UV radiation is invariably damaging to eye tissues by the formation of free radicals [8]. Both UV-A and UV-B may cause skin disorders, skin cancers and many diverse ocular disorders including senile cataract, pterygium, photokeratitis, photoconjunctivitis, and ocular melanoma [1] [3]-[6]. Many epidemiologic studies showed that latitude and sunlight hours are positively correlated with the incidence of various ocular diseases such as pterygium, cataract, and ocular surface squamous neoplasia [6] [9] [10]. Each individual is exposed to a variable amount of UVR, which is dependent on many environmental factors such as latitude and altitude and personal behaviours such as the use of protective clothing and sunglasses. Out of these factors, the personal protection measures, including the use of brimmed hats and sunglasses were shown to be the most modifiable ones. They can effectuate up to an 18-fold difference in ocular UVR exposure [11].

There are three main standards for sunglasses in the world. These are the Australian, United Stated, and European standards [12]. Ideally sunglasses should absorb the entire UV spectrum including UV-A and UV-B [11]. Sunglasses are classified according to the LT based on the European standard for sunglasses. The ones with the LT $\%<18$ are classified in Category 3 and 4 . These should satisfy the requirements for UVR transmittance to provide good protection from UVR. Category 2 provides some UVR protection, if meets the criteria, while the other 2 categories are fashion spectacles without providing adequate UVR protection. In the current study, none of the sunglasses were fashion spectacles based on their LT and all of them satisfied the requirements for the UV-B transmittance regardless of their prices. However, three Category 3 and one Category 2 sunglasses of Group A and one Category 4, one Category 3 and two Category 2 sunglasses of Group B were non-compliant with the European standard based on their UV-A transmittance \%. Among UVR types, all of the UV-C and 90\% of UV-B radiations are filtered by the ozone layer, so UV-A is the most prevalent one in nature [13]. Although, both UV-A and B have harmful effects on human eye and skin, UV-B radiation was shown to be more damaging 
on human lenses, cornea, conjunctiva and skin than UV-A radiation [1] [3]-[6] [14]. The link between age related macular degeneration and UVR is controversial [15] [16]. It is proposed that visible light, especially blue light, is one of the etiologic factors for the development of AMD [17]. According to our findings, some of the sunglasses did not meet the criteria for their categories regarding UV-A transmittance, so should be labelled as fashion spectacles.

Australia is the only country where the sunglass standards are directly enacted in law [18]. All sunglasses sold in Australia must be labelled indicating the \% of UVR protection and $100 \%$ protection is considered a good level [12]. There is no mandatory testing in other countries. There are several studies in which the sunglasses are evaluated for their compliance with the standards [18]-[20]. In a study conducted by the "Optics and Radiometry Laboratory" 20\% noncompliance was reported with the European standards [18]. Ultraviolet radiation protection was not satisfactory in another study performed in India [19]. On the other hand UVR protection was shown to be satisfactory in a study from Poland [20].

In the current study, \% transmittance of visible light was also evaluated. Some of the sunglasses were shown to transmit less than $8 \%$ of the visible light regardless of their prices. This had to be indicated, because the minimum visible light transmittance requirement for driving is $8 \%$ according to the sunglass standards [7]. Besides the UVR protection the sunglasses should meet other requirements to be certified. These additional requirements are related to the refractive power, prismatic power, and polarization [12] [18]. These properties enable higher visual acuity while providing UVR protection. We did not evaluate these properties, but some noncompliance with the regulations regarding the transmittance spectrum was detected.

Based on our findings, regardless of their prices, some of the unbranded sunglasses were non-compliant with the European standard for sunglasses and some of them were not appropriate to wear when driving. Therefore, optometrists and ophthalmologists should warn the consumers against wearing unbranded sunglasses without any specifications, to provide protection from UVR and also when driving.

According to our findings some of the sunglasses did not meet the criteria for their categories regarding UV-A transmittance, so should be labelled as fashion spectacles. Also the visible light transmittance was less than $8 \%$. This had to be indicated, because the minimum visible light transmittance requirement for driving is $8 \%$ according to the sunglass standards. Two things can be done to solve the problem: enact laws like in Australia, or publicize the findings and enhance customer knowledge about the need to have details specifications about UV and visible light transmission and customers should not wear except glasses with certificates that meet the safety standards.

\section{References}

[1] Weinstock, M.A. (1995) Overview of Ultraviolet Radiation and Cancer: What Is the Link? How Are We Doing? Environmental Health Perspectives, 103, 251-54. http://dx.doi.org/10.1289/ehp.95103s8251

[2] Fioletov, V., Kerr, J.B. and Fergusson, A. (2010) The UV Index: Definition, Distribution and Factors Affecting It. Canadian Journal of Public Health, 101, 15-19.

[3] Boettner, E.A. and Wolter, J.R. (1962) Transmission of the Ocular Media. Investigative Ophthalmology \& Visual Science, 1, 776-83.

[4] Ambach, W., Blumthaler, M., Schopf, T., Ambach, E., Katzgraber, F., Daxecker, F., et al. (1994) Spectral Transmission of the Optical Media of the Human Eye with Respect to Keratitis and Cataract Formation. Documenta Ophthalmologica, 88, 165-73. http://dx.doi.org/10.1007/BF01204614

[5] Gallagher, R.P. and Lee, T.K. (2006) Adverse Effects of Ultraviolet Radiation: A Brief Review. Progress in Biophysics and Molecular Biology, 92, 119-31. http://dx.doi.org/10.1016/j.pbiomolbio.2006.02.011

[6] Moran, D.J. and Hollows, F.C. (1984) Pterygium and Ultraviolet Radiation: A Positive Correlation. British Journal of Ophthalmology, 68, 343-346. http://dx.doi.org/10.1136/bjo.68.5.343

[7] European Standards Organisation (CEN) 2005 EN 1836 Personal Eye Protection: Sunglasses and Sunglare Filters for General Use and Filters for Direct Observation of the Sun: EN 1836:2005. CEN, Brussels.

[8] Kulms, D. and Schwarz, T. (2002) Molecular Mechanisms Involved in UV-Induced Apoptotic Cell Death. Skin Pharmacology and Physiology, 15, 342-47. http://dx.doi.org/10.1159/000064539

[9] Schein, O.D., West, S., Munoz, B., et al. (1994) Cortical Lenticular Opacification: Distribution and Location in a Longitudinal Study. Investigative Ophthalmology \& Visual Science, 35, 363-66.

[10] Newton, R. (1996) A Review of the Aetiology of Squamous Cell Carcinoma of the Conjunctiva. British Journal of Cancer, 74, 1511-513. http://dx.doi.org/10.1038/bjc.1996.581 
[11] Rosenthal, F.S., West, S.K., Munoz, B., Emmett, E.A., Strickland, P.T. and Taylor, H.R. (1991) Ocular and Facial Skin Exposure to Ultraviolet Radiation in Sunlight: A Personal Exposure Model with Application to a Worker Population. Health Physics, 61, 77-86. http://dx.doi.org/10.1097/00004032-199107000-00008

[12] Dain, S.J. (2003) Sunglasses and Sunglass Standards. Clinical and Experimental Optometry, 86, 77-90. http://dx.doi.org/10.1111/j.1444-0938.2003.tb03066.x

[13] WMO (1995) Scientific Assessment of Ozone Depletion: 1994. World Meteorlogical Organization, Global Ozone Research and Monitoring Project, Report No. 37, Geneva.

[14] Kessel, L., Eskildsen, L., Lundeman, J.H., Jensen, O.B. and Larsen, M. (2011) Optical Effects of Exposing Intact Human Lenses to Ultraviolet Radiation and Visible Light. BMC Ophthalmology, 11, 41. http://dx.doi.org/10.1186/1471-2415-11-41

[15] Darzins, P., Mitchell, P. and Heller, R.F. (1997) Sun Exposure and Age-Related Macular Degeneration. An Australian Case-Control Study. Ophthalmology, 104, 770-776. http://dx.doi.org/10.1016/S0161-6420(97)30235-8

[16] Cruickshanks, K.J., Klein, R. and Klein, B.E. (1993) Sunlight and Age-Related Macular Degeneration. The Beaver Dam Eye Study. Archives of Ophthalmology, 111, 514-518. http://dx.doi.org/10.1001/archopht.1993.01090040106042

[17] Taylor, H.R., Munoz, B., West, S., Bressler, N.M., Bressler, S.B. and Rosenthal, F.S. (1990) Visible Light and Risk of Age-Related Macular Degeneration. Transactions of the American Ophthalmological Society, 88, 163-173.

[18] Dain, S.J., Ngo, T.P., Cheng, B.B., Hu, A., Teh, A.G.B., Tseng, J. and Vu, N. (2010) Sunglasses, the European Directive and the European Standard. Ophthalmic and Physiological Optics, 30, 253-256. http://dx.doi.org/10.1111/j.1475-1313.2010.00711.x

[19] Dongre, A.M., Pai, G.G. and Khopkar, U.S. (2007) Ultraviolet Protective Properties of Branded and Unbranded Sunglasses Available in the Indian Market in UV Phototherapy Chambers. Indian Journal of Dermatology, Venereology and Leprology, 73, 26-28. http://dx.doi.org/10.4103/0378-6323.30647

[20] Cader, A. and Jankowski, J. (1996) Evaluation of Protective Properties of Sunglasses Commonly Available in the Marketplace. Medycyna Pracy, 47, 365-371. 
Scientific Research Publishing (SCIRP) is one of the largest Open Access journal publishers. It is currently publishing more than 200 open access, online, peer-reviewed journals covering a wide range of academic disciplines. SCIRP serves the worldwide academic communities and contributes to the progress and application of science with its publication.

Other selected journals from SCIRP are listed as below. Submit your manuscript to us via either submit@scirp.org or Online Submission Portal.
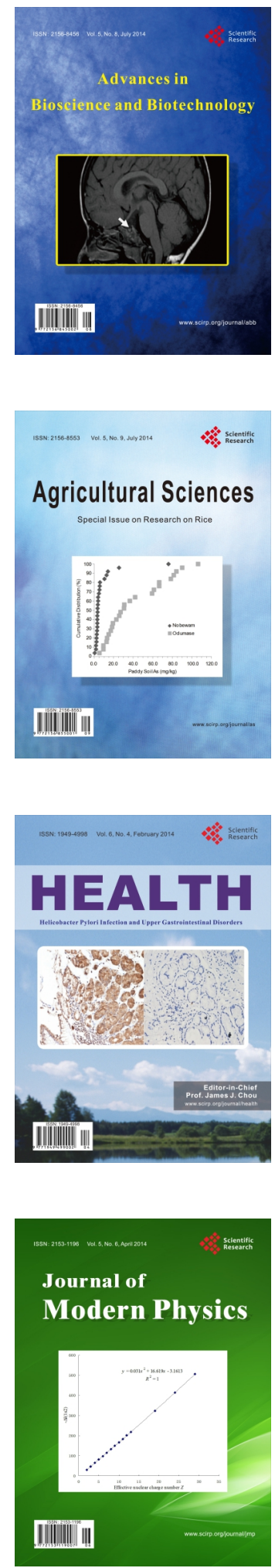
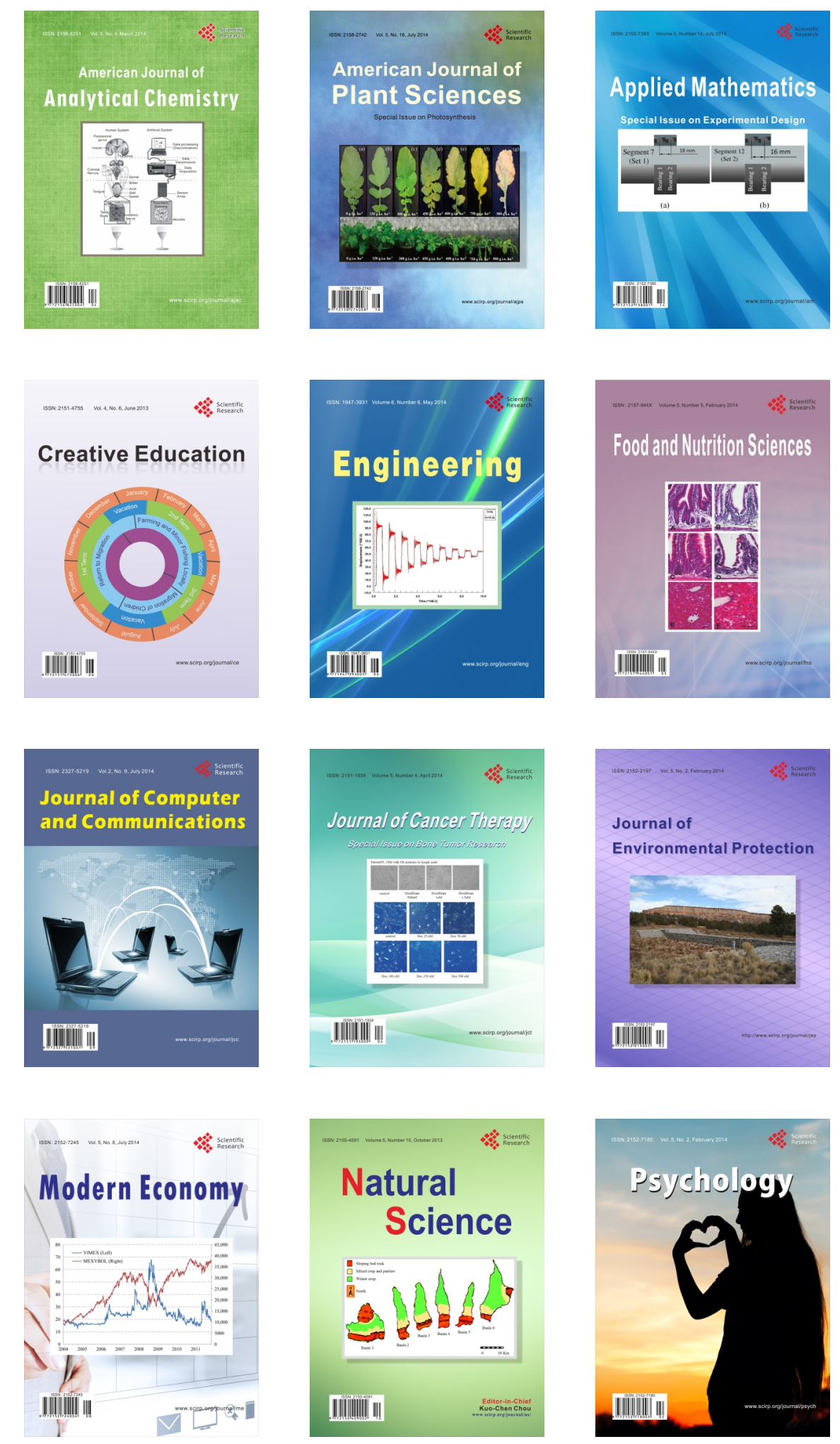